\title{
A glimpse of the future? - bronchoscopic ablation of peripheral early stage lung cancer
}

\author{
Daniel P. Steinfort ${ }^{1,2}$, Kanishka Rangamuwa ${ }^{1,2}$ \\ ${ }^{1}$ Department of Respiratory, Royal Melbourne Hospital, Melbourne, Australia; ${ }^{2}$ Department of Medicine, Faculty of Medicine, Dentistry \& Health \\ Sciences, University of Melbourne, Melbourne, Australia \\ Correspondence to: Daniel P. Steinfort. Department of Respiratory, Royal Melbourne Hospital, 300 Grattan St., Parkville 3050, Melbourne, Australia. \\ Email: daniel.steinfort@mh.org.au. \\ Comment on: Bao F, Yu F, Wang R, et al. Electromagnetic bronchoscopy guided microwave ablation for early stage lung cancer presenting as ground \\ glass nodule. Transl Lung Cancer Res 2021;10:3759-70.
}

Submitted Sep 15, 2021. Accepted for publication Sep 29, 2021.

doi: $10.21037 /$ tlcr-21-763

View this article at: https://dx.doi.org/10.21037/tlcr-21-763

The rapid expansion of the field of Interventional Pulmonology was initially driven by diagnostic techniques, but more recently has extended into therapeutic interventions. These initially were for airway disease including emphysema (1) and chronic bronchitis (2), but with development of flexible ablation probes, the potential for bronchoscopic therapy of peripheral lung cancer is now closer than ever. Bronchoscopic tumour ablation offers the promise of minimally invasive lung-sparing curative-intent therapy of pulmonary tumours, with a safety likely to be significantly superior to percutaneous ablation modalities. In this issue of Translational Lung Cancer Research, Bao and colleagues present exciting new data regarding a novel microwave ablation (MWA) catheter, combined with electromagnetic navigation (EMN) guidance for treatment of ground-glass lesions in patients with multi-focal lung adenocarcinoma (3). Their study is a further step towards bronchoscopic treatment for lung cancer, and illustrates how such technology may alter treatment paradigms in future for patients with localized lung tumours.

Surgical resection has historically been the standard of care for early stage non-small cell lung cancer. Lobectomy is recommended, and consequently patients may lose a significant amount of lung parenchyma even for small lesions. Despite extensive resection, recurrence of disease in Stage I patients occurs in $20-30 \%$ of patients, and frequently occurs early-median time to recurrence is approximately $12-17$ months (4-6). Peri-operative mortality following lobectomy exceeds $1.5 \%$ and does not appear to be smaller following sub-lobar resection (7). Even for a gold standard, surgical resection leaves much room for improvement.

Additionally, surgery is precluded in many patients, either due to co-existent medical co-morbidities (8), advanced age/frailty (9), or multiple synchronous primaries, or multi-focal adenocarcinoma. Up to $25 \%$ of patients with radiologically resectable disease are medically inoperable and thus, effective and safe minimally invasive therapies for pulmonary malignancy are keenly needed.

Multiple percutaneous ablation modalities are available established, with MWA, radiofrequency ablation (RFA), and cryoablation all reported to achieve reasonable local control of Stage I NSCLC. Their use is significantly limited by high rates of complications observed due to the percutaneous introduction of the ablation probes. Pneumothorax rates may exceed $60 \%$ (10) with intercostal drains required in $8-38 \%$ (11), which is clearly problematic for a modality likely to be applied in multiply co-morbid patients. Safety concerns may also preclude use in central tumours, or those in close proximity to chest wall or mediastinal structures. Isolated reports of needle tract seeding following percutaneous ablation are rare but have been reported following RFA and MWA (12).

Bronchoscopic ablation of peripheral tumours was first reported in 2010 (13), but until recently the only modality used in clinical studies was RFA, and even then, only by two groups (12). The publication by Bao and colleagues is just the second report on EMN-guided MWA for treatment 
of peripheral NSCLC, following the study by Chan and colleagues, also published in Translational Lung Cancer Research earlier this year (14). Bao and colleagues have used EMN guidance to accurately target fifteen sub-sold lesions ranging from 5-17 $\mathrm{mm}$ (only three were larger than $11 \mathrm{~mm}$. Their findings clearly establish technical efficacy and safety of bronchoscopic MWA for ablation of parenchymal lesions. The primary outcome of ablation efficacy, established by radiologic evidence of target lesion ablation on CT 1-week following RFA, was achieved in 11 of 15 patients (73\%).

The study also hints at some paradigm changes that may accompany development of bronchoscopic therapy for localized lung cancers-use of rapid on-site cytology to establish intra-procedural diagnosis (and obviate a standalone diagnostic procedure) (15), and treatment in the absence of tissue confirmation, as was performed in two patients in this study. Positive predictive value of ROSE examination of bronchial brushings is extremely high (15), and "empiric" stereotactic radiotherapy (SABR) is frequently utilized for stage I NSCLC given the risks of biopsy frequently exceed the risks of SABR (16).

There are some procedural aspects that may need to be incorporated into future studies to improve technical success. Importantly both studies appear to be clinical case series, which may help explain why clinical features of four patients where effective ablation was not demonstrated on CT are not presented. We therefore do not know if this due to insufficient ablation volume, in which case increased energy dose (not reported in this study) may be required. Or was it due to inaccurate targeting, in which case localization tools may be required. Importantly, EMN is a "guidance" tool, and does not provide target localization. Studies reporting accuracy of EMN-guided pleural tattoo are instructive in illustrating that EMN guidance is not $100 \%$ accurate (17).

In contrast, endobronchial ultrasound (EBUS) is able to confirm the localization of peripheral lesions prior to treatment. EMN improves the EBUS localization rate of peripheral tumours by approximately $30 \%$ (18), suggesting it is likely in future that multiple modalities may be required to ensure accurate targeting of ablation. The retrospective series by Chen \& colleagues (14) utilized EMN guidance together with cone-beam CT intra-procedural imaging to confirm accurate probe positioning within the target lesion to achieve EMN ablation in biopsy-confirmed NSCLC ranging 7-29 $\mathrm{mm}$ diameter. Perhaps as a result they achieved technical success (defined a priori as inclusion of lesion into ablation zone with minimum of $5 \mathrm{~mm}$ margin around lesion) in $100 \%$ of cases. This study also reported radiologic outcomes at six months for 15 of 30 patients, with complete response achieved in 1 patient, partial response in 12 patients, and stable disease in the remaining 2 patients.

While feasibility and technical success is established in both studies, what clearly remains to be established is clinical efficacy. Future prospective registered studies of bronchoscopic MWA establishing disease-specific local control, and overall survival will be needed before this modality is ready for clinical use. As the authors note, microscopic foci of residual tumor is impossible to identify on imaging. Indeed, a treat-and-resect study completed at our institution examining efficacy of bronchoscopic thermal vapor ablation for minimally invasive treatment of localized lung cancer demonstrated viable tumour within the radiologic ablation zone in 1 of 4 patients (19). Equally, despite percutaneous MWA ablation with apparent complete ablation, 1-year progression-free survival is only $65 \%(20)$.

In addition to the suggested paradigm changes including ROSE, or empiric treatment of suspicious lesions, future studies may also incorporate other novel paradigm elements. Given systematic lymph node staging, routine at the time of lobectomy, will not be performed, systematic EBUS-guided lymph node staging $(21,22)$ may be performed at the time of therapeutic bronchoscopic to ensure absence of lymph node metastases (which would preclude use of localized ablative therapies), or use of validated models for prediction of lymph node metastases (23) may be incorporated into routine pre-procedure work-up to identify those at high risk of PET-occult lymph node involvement. Equally, given the apparent safety \& accuracy of bronchoscopic thermal ablation of lung tumours, MWA or other modalities may be use to elicit an anticancer immune response (24), augmenting immune checkpoint inhibitors and other immunotherapies (25).

We warmly congratulate Bao \& colleagues on their study which marks a significant advance in the expanding field of interventional pulmonology. In addition to demonstrating the feasibility and technical success of bronchoscopic MWA for ablation of ground-glass lung lesions, they have taken an even more significant step in demonstrating a new paradigm for therapeutic combinations and patient selection for minimally invasive treatment of lung cancer. Future success in establishing bronchoscopic therapies for treatment of pulmonary malignancies will be built upon studies such as this one, and we should all be grateful for their work. 


\section{Acknowledgments}

Funding: None.

\section{Footnote}

Provenance and Peer Review: This article was commissioned by the editorial office, Translational Lung Cancer Research. The article did not undergo external peer review.

Conflicts of Interest: Both authors have completed the ICMJE uniform disclosure form (available at https://dx.doi. org/10.21037/tlcr-21-763). DPS serves as an unpaid editorial board member of Translational Lung Cancer Research. DPS reports Honoraria from Astra Zeneca, and Institutional research funds from Broncus medical \& Zidfan Medical. The other author has no conflicts of interest to declare.

Ethical Statement: The authors are accountable for all aspects of the work in ensuring that questions related to the accuracy or integrity of any part of the work are appropriately investigated and resolved.

Open Access Statement: This is an Open Access article distributed in accordance with the Creative Commons Attribution-NonCommercial-NoDerivs 4.0 International License (CC BY-NC-ND 4.0), which permits the noncommercial replication and distribution of the article with the strict proviso that no changes or edits are made and the original work is properly cited (including links to both the formal publication through the relevant DOI and the license). See: https://creativecommons.org/licenses/by-nc-nd/4.0/.

\section{References}

1. Herth FJF, Slebos DJ, Criner GJ, et al. Endoscopic Lung Volume Reduction: An Expert Panel Recommendation Update 2019. Respiration 2019;97:548-57.

2. Valipour A, Fernandez-Bussy S, Ing AJ, et al. Bronchial Rheoplasty for Treatment of Chronic Bronchitis. TwelveMonth Results from a Multicenter Clinical Trial. Am J Respir Crit Care Med 2020;202:681-9.

3. Adler I. Primary malignant growths of the lungs and bronchi: A pathological and clinical study. Longmans, Green, 1912.

4. Kelsey CR, Marks LB, Hollis D, et al. Local recurrence after surgery for early stage lung cancer: an 11-year experience with 975 patients. Cancer 2009;115:5218-27.
5. Guerrera F, Lococo F, Evangelista A, et al. Risk of recurrence in stage I adenocarcinoma of the lung: a multiinstitutional study on synergism between type of surgery and type of nodal staging. J Thorac Dis 2019;11:564-72.

6. Hung JJ, Jeng WJ, Hsu WH, et al. Prognostic factors of postrecurrence survival in completely resected stage I non-small cell lung cancer with distant metastasis. Thorax 2010;65:241-5.

7. Altorki NK, Wang X, Wigle D, et al. Perioperative mortality and morbidity after sublobar versus lobar resection for early-stage non-small-cell lung cancer: post-hoc analysis of an international, randomised, phase 3 trial (CALGB/Alliance 140503). Lancet Respir Med 2018;6:915-24.

8. Ricardi U, Badellino S, Filippi AR. Stereotactic body radiotherapy for early stage lung cancer: History and updated role. Lung Cancer 2015;90:388-96.

9. Vazirani J, Moraes J, Barnett S, et al. Outcomes following resection of non-small cell lung cancer in octogenarians. ANZ J Surg 2018;88:1322-7.

10. Inoue M, Nakatsuka S, Jinzaki M. Cryoablation of early-stage primary lung cancer. Biomed Res Int 2014;2014:521691.

11. Zhao ZR, Lau RWH, Ng CSH. Catheter-based alternative treatment for early-stage lung cancer with a high-risk for morbidity. J Thorac Dis 2018;10:S1864-70.

12. Steinfort DP, Herth FJF. Bronchoscopic treatments for early-stage peripheral lung cancer: Are we ready for prime time? Respirology 2020;25:944-52.

13. Tanabe T, Koizumi T, Tsushima K, et al. Comparative study of three different catheters for CT imagingbronchoscopy-guided radiofrequency ablation as a potential and novel interventional therapy for lung cancer. Chest 2010;137:890-7.

14. Chan JWY, Lau RWH, Ngai JCL, et al. Transbronchial microwave ablation of lung nodules with electromagnetic navigation bronchoscopy guidance-a novel technique and initial experience with 30 cases. Transl Lung Cancer Res 2021;10:1608-22.

15. Steinfort DP, Leong TL, Laska IF, et al. Diagnostic utility and accuracy of rapid on-site evaluation of bronchoscopic brushings. Eur Respir J 2015;45:1653-60.

16. Park J, Whiting C, Reddy E, et al. Factors Associated with Radiation Toxicity and Survival in Patients with Presumed Early-Stage Non-Small Cell Lung Cancer Receiving Empiric Stereotactic Ablative Radiotherapy. Fed Pract 2021;38:S30-4.

17. Tay JH, Wallbridge PD, Larobina M, et al. 
Electromagnetic Navigation Bronchoscopy-directed Pleural Tattoo to Aid Surgical Resection of Peripheral Pulmonary Lesions. J Bronchology Interv Pulmonol 2016;23:245-50.

18. Steinfort DP, Bonney A, See K, et al. Sequential multimodality bronchoscopic investigation of peripheral pulmonary lesions. Eur Respir J 2016;47:607-14.

19. Steinfort DP, Christie M, Antippa P, et al. Bronchoscopic Thermal Vapour Ablation for Localized Cancer Lesions of the Lung: A Clinical Feasibility Treat-and-Resect Study. Respiration 2021;100:432-42.

20. Yuan Z, Wang Y, Zhang J, et al. A Meta-Analysis of Clinical Outcomes After Radiofrequency Ablation and Microwave Ablation for Lung Cancer and Pulmonary Metastases. J Am Coll Radiol 2019;16:302-14.

21. Leong TL, Loveland PM, Gorelik A, et al. Preoperative Staging by EBUS in cN0/N1 Lung Cancer: Systematic Review and Meta-Analysis. J Bronchology Interv Pulmonol 2019;26:155-65.

Cite this article as: Steinfort DP, Rangamuwa K. A glimpse of the future?-bronchoscopic ablation of peripheral early stage lung cancer. Transl Lung Cancer Res 2021;10(10):3861-3864. doi: $10.21037 /$ tlcr-21-763
22. Steinfort DP, Siva S, Leong TL, et al. Systematic Endobronchial Ultrasound-guided Mediastinal Staging Versus Positron Emission Tomography for Comprehensive Mediastinal Staging in NSCLC Before Radical Radiotherapy of Non-small Cell Lung Cancer: A Pilot Study. Medicine (Baltimore) 2016;95:e2488.

23. Martinez-Zayas G, Almeida FA, Yarmus L, et al. Predicting Lymph Node Metastasis in Non-small Cell Lung Cancer: Prospective External and Temporal Validation of the HAL and HOMER Models. Chest 2021;160:1108-20.

24. Rangamuwa $\mathrm{K}$, Leong $\mathrm{T}$, Bozinovski S, et al. Increase in tumour PD-L1 expression in non-small cell lung cancer following bronchoscopic thermal vapour ablation. Transl Lung Cancer Res 2021;10:2858-64.

25. Rangamuwa K, Leong T, Weeden C, et al. Thermal ablation in non-small cell lung cancer: a review of treatment modalities and the evidence for combination with immune checkpoint inhibitors. Transl Lung Cancer Res 2021;10:2842-57. 